1 Department of Dental Materials and Prosthodontic. Aracatuba School of Dentistry, Sao Paulo State University (UNESP), Araçatuba, SP, Brazil.

${ }^{2}$ Department of Restorative Dentistry, Faculty of Dentistry, Federal University of Minas Gerais (UFMG). Belo Horizonte, MG, Brazil.

${ }^{3}$ Department of Physics and Chemistry. Faculty of Ilha Solteira, São Paulo State University (UNESP). Ilha Solteira, SP, Brazil.

Corresponding author:

Professor Paulo Henrique dos Santos Department of Dental Materials and Prosthodontics

Araçatuba School of Dentistry UNESP

Rua José Bonifácio, 1193, Zip code 16015-050 Araçatuba, SP - BRAZIL Phone: +551836362802

Fax: +551836363245

E-mail: paulosantos@foa.unesp.br

Received: November 21, 2018

Accepted: April 05, 2019

\section{Degree of conversion of resin cements polymerized under different thicknesses of feldspathic porcelain}

\author{
Marcio Leandro Von Dreifus Marinho ${ }^{1}$, Thaís Yumi \\ Umeda Suzuki ${ }^{2}$, Wirley Gonçalves Assunção ${ }^{1}$, João \\ Carlos Silos Moraes ${ }^{3}$, Paulo Henrique dos Santos ${ }^{1, *}$
}

Aim: The aim of this study is to evaluate the degree of conversion (DC) of resin cements polymerized under different thicknesses of feldspathic dental ceramic. Methods: Forty samples of RelyX ARC and RelyX Veneer resin cements were polymerized under Starlight feldspathic ceramic discs (DeguDent Gmbh) with $0.5 \mathrm{~mm}, 1.2 \mathrm{~mm}, 1.8 \mathrm{~mm}$, and 2.4 $\mathrm{mm}$ in thickness. The control group was cured without the interposition of ceramic. The DC measurements were performed 10 minutes, 1 hour, and 24 hours after the lightactivation in a Nexus 670 FTIR spectrophotometer. Data were analyzed by two-way repeated measure ANOVA and Fisher PLSD test. Results: The RelyX ARC showed higher DC for all ceramic thicknesses. There was significant decrease in DC related to an increase in ceramic thickness. For RelyX ARC, the values of DC obtained after 1 hour and 24 hours did not differ statistically between them, but they were higher than those analyzed after 10 minutes. For RelyX Veneer cement, there was gradual increase in the DC up to 24 hours. Conclusion: The higher the thicknesses of ceramic, the lower DC of the resin cement.

Keywords: Ceramics. Polymerization. Resin cements. 


\section{Introduction}

The color and appearance of teeth are complex phenomena influenced by many factors, including the condition, light scattering, translucency, opacity and brightness of the substrate ${ }^{1}$. Recently, new ceramic materials have been developed in an attempt to achieve the qualities of natural teeth, joining aesthetic factors with increased material resistance ${ }^{2,3}$.

Dental ceramic is highly appreciated as a restorative material with great aesthetic properties that best simulate natural dentition ${ }^{4,5}$. Other features present are translucency ${ }^{6}$, fluorescence, chemical stability, biocompatibility, high compressive strength and coefficient of thermal expansion similar to the structure denta ${ }^{7,8}$. In contradiction to these advantages, ceramics exhibit weakness in their tension efforts ${ }^{8}$. This disadvantage can be attributed to the amount of microcracks into the matrix of some ceramic systems, that make them susceptible to fracture during cementation or high occlusal forces ${ }^{9}$.

A decisive factor for the success of ceramic restoration is the proper curing of luting resin cement ${ }^{10,11}$, ensuring the high mechanical properties ${ }^{10,12}$, and satisfactory clinical performance of the material ${ }^{10}$. An inadequate polymerization, characterized by a low degree of chemical conversion of carbon double bonds into simple bonds ${ }^{13-15}$, can decrease the physical properties of the composite, compromising the bond strength of the prosthetic restoration to the teeth ${ }^{13}$. The calculation of the degree of conversion (DC) is based on the proportion of the decrease in the intensity of the stretching band of $\mathrm{C}=\mathrm{C}$ methacrylate ${ }^{16}$. According to Akgungor et al. ${ }^{2}(2005)$, the DC of resin cement is dependent on the type and thickness of restorative material used, and there is a reduction in its value with decreasing light intensity 17,18 .

An advanced technique for studies of DC is by Fourier transform infrared spectroscopy (FTIR), which appears to be very effective for data acquisition and offers a direct approach to addressing the depth of cure of dental composites by the DC in monomer polymerization ${ }^{19}$. Although there are studies in the literature based on the biomechanical properties of dental ceramics, especially found on the flexural strength, fracture, wear, modulus of elasticity, and marginal accuracy of fit $20-23$, there are few studies that deal with the analysis of the DC of resin cements in relation to the ceramic thickness and different mode of light over time ${ }^{10,24,25}$. Studies in this direction are important, since an adequate polymerized resin cement would contribute to the satisfactorily transmission of force to the tooth, also relieving the stresses to the bone and support structures ${ }^{26,27}$. Therefore, the purpose of this study was to evaluate the degree of conversion of dual and light-cured resin luting cements under different feldsphatic ceramic thickness over time. Three null hypotheses were tested: (1) there was no difference in the DC between dual and light-cured resin cements, (2) the DC of these cements did not get better over time and (3) the thickness of feldsphatic ceramic did not influence the DC of resin cements.

\section{Materials and methods}

Four discs of feldsphatic ceramics (Starlight, DeguDent, Hanau, Germany) were prepared using a silicone matrix, measuring $20 \mathrm{~mm}$ in diameter, with a thickness of 
$0.5 \mathrm{~mm}, 1.2 \mathrm{~mm}, 1.8 \mathrm{~mm}$, or $2.4 \mathrm{~mm}$. The oven for ceramic (Centurion VPC, NEY, Dentsply, York, PA, USA) with an initial temperature of $500^{\circ} \mathrm{C}$, speed of rise $65^{\circ} \mathrm{C} / \mathrm{min}$, and final temperature of $910^{\circ} \mathrm{C}$ was used for sintering of ceramics. After sintering, finishing and polishing of the surfaces was carried out with stones and diamond burs, sandblasted with aluminum oxide and glazed. The final measure of the samples was checked with a digital caliper.

Two resin cements were used in this study: a light cured RelyX Veneer (3M Espe, St. Paul, USA) and a dual-cured RelyX ARC (3M Espe) (Table 1). The cements were placed in an aluminum matrix measuring $15 \mathrm{~mm}$ in diameter and $0.1 \mathrm{~mm}$ thick on a glass slide. On the cement, a glass cover slip was accommodated, and the cements were light-cured for 40 seconds using Ultraled II with minimum light output of $700 \mathrm{~mW} / \mathrm{cm}^{2}$ (Dabi Atlante, Ribeirão Preto, Brazil) interposing between the light source and resin cement for the ceramic discs with different thickness. The control group received polymerization of the cement without the ceramic disc interposition.

Forty samples were prepared for each resin cement according to the thickness of the ceramic $(n=8)$. The resin cements' DC measurements were performed after 10 minutes, 1 hour, and 24 hours using a Nexus 670 FT-IR spectrophotometer (Nicolet Instrument Corp. Madison, WI, USA), for the transmission method, operating with 64 scan at a resolution of $4 \mathrm{~cm}^{-1}$ within a wavelength of $4800-4500 \mathrm{~cm}^{-1}$. The direct way to determine the degree of polymerization conversion was based on the extent of the decrease in intensity of the $=\mathrm{CH}_{2}$ stretching band of the methacrylate, when the monomer is converted to polymer. This spectroscopic procedure depends on the presence of an absorption band that does not change with polymerization, and it serves as a standard for normalization of the spectra of the monomer and polymer.

$$
D C=\left(1-\frac{C}{U}\right) \times 100^{19}
$$

Where $\mathrm{C}$ and $\mathrm{U}$ are ratios of intensity between absorptions $\mathrm{CH}_{2}=$ aliphatic and aromatic before and after polymerization, respectively. In this manner, the percentage of carbonic double bonds that did not react during the polymerization reaction is determined. The DC is determined by subtracting the residual percentage from 100\%. Data were analyzed by three-way repeated measure ANOVA and Fisher PLSD test $(a=0.05)$.

Table 1. Materials used in the study.

\begin{tabular}{lccc}
\hline Trademark & Batch \# & Composition* & Manufacturer \\
\hline RelyX ARC & GA8JA2010-05 & $\begin{array}{c}\text { Base paste: Bis GMA, TEGDMA, } \\
\text { Peróxido de Benzoíla. } \\
\text { Catalyst paste: Bis GMA, TEGDMA, } \\
\text { photoinitiator system, amine, peroxide, } \\
\text { zirconia/sílica filler 67,5\% by weight }\end{array}$ & St. Paul, MN, USA \\
\hline RelyX Veener & 8EA2010-07 & Bis GMA,TEGDMA, zirconia/sílica & 3M ESPE, St. Paul, \\
filler 66\% by weight & MN, USA \\
\hline
\end{tabular}

${ }^{\star}$ According to manufacturers. 


\section{Results}

The three-way ANOVA showed statistically significant differences among the resin cements $(p<0.0001)$, the different thicknesses of ceramic feldspathic $(p<0.0001)$, and the different periods studied ( $p<0.0001)$.

Table 2 shows the DC average for the dual resin cement. In general, the samples tested after 10 minutes had lower DC compared with the samples tested after 1 hour and 24 hours $(p<0.0001)$. There was no statistically significant difference between the values of conversion degree obtained after 1 hour and 24 hours $(p=0.7433)$. Comparing the thickness of ceramics, the highest degrees of conversion were obtained for samples without the interposition of ceramic and with $1.2 \mathrm{~mm}$ in thickness $(p=0.1770)$. There was a significant decrease in the DC corresponding with the increase in ceramic thickness of $1.8 \mathrm{~mm}$ and $2.4 \mathrm{~mm}$ ( $p<0.0001)$.

Table 3 shows the DC for the light-cured resin cement. The samples evaluated after 10 minutes had a lower DC compared with the samples tested after 1 hour and 24 hours $(p<0.0001)$. The highest values of DC were obtained after 24 hours $(p<0.0001)$. Comparing the thickness of ceramics, the highest degrees of conversion were obtained for the samples without the interposition of ceramic $(p<0.0001)$, and there was no statistically significant difference between the thicknesses of $0.5 \mathrm{~mm}$ and $1.2 \mathrm{~mm}(\mathrm{p}=0.5142)$. There was a significant decrease in the DC,

Table 2. Degree of conversion of the dual-cured RelyX ARC resin cement.*

\begin{tabular}{ccccc}
\hline & 10 minuts & 1 hour & 24 hours & Pooled data \\
\hline No ceramics & $66.85(1.70)$ & $71.99(1.15)$ & $69.34(0.84)$ & $69.39(1.23) \mathrm{a}$ \\
\hline $0,5 \mathrm{~mm}$ & $61.67(1.18)$ & $64.60(1.27)$ & $75.59(0.43)$ & $67.28(0.96) \mathrm{b}$ \\
\hline $1,2 \mathrm{~mm}$ & $67.16(1.69)$ & $71.27(1.04)$ & $67.15(1.81)$ & $68.52(1.51) \mathrm{ab}$ \\
\hline $1,8 \mathrm{~mm}$ & $63.67(2.14)$ & $68.80(1.43)$ & $65.44(1.56)$ & $65.97(1.71) \mathrm{c}$ \\
\hline $2,4 \mathrm{~mm}$ & $55.58(3.08)$ & $65.67(1.73)$ & $64.24(3.22)$ & $61.83(2.67) \mathrm{d}$ \\
\hline Pooled data & $62.99(1.95) \mathrm{B}$ & $68.47(1.32) \mathrm{A}$ & $68.35(1.57) \mathrm{A}$ & \\
\hline
\end{tabular}

* Means followed by distinct letters. Capital letters among columns and lower case letters among rows are significantly different (5\%)

Table 3. Degree of conversion of the light cured RelyX Veener resin cement.*

\begin{tabular}{ccccc}
\hline & 10 minuts & 1 hour & 24 hours & Pooled data \\
\hline No ceramics & $59.45(0.78)$ & $62.75(0.71)$ & $60.62(2.49)$ & $60.94(1.32) \mathrm{a}$ \\
\hline $0,5 \mathrm{~mm}$ & $50.12(1.07)$ & $54.15(1.01)$ & $65.56(1.07)$ & $56.61(1.05) \mathrm{b}$ \\
\hline $1,2 \mathrm{~mm}$ & $55.15(1.81)$ & $59.49(1.09)$ & $53.88(1.89)$ & $56.17(1.59) \mathrm{b}$ \\
\hline $1,8 \mathrm{~mm}$ & $44.02(1.63)$ & $49.56(1.44)$ & $59.28(1.96)$ & $50.95(1.67) \mathrm{c}$ \\
\hline $2,4 \mathrm{~mm}$ & $38.66(1.43)$ & $43.72(1.47)$ & $48.95(2.31)$ & $43.77(1.73) \mathrm{d}$ \\
\hline Pooled data & $49.48(1.34) \mathrm{C}$ & $53.93(1.14) \mathrm{B}$ & $57.95(1.94) \mathrm{A}$ & \\
\hline
\end{tabular}

* Means followed by distinct letters. Capital letters among columns and lower case letters among rows are significantly different (5\%) 
as increased the thickness of the ceramic increased from $0.5 \mathrm{~mm}$ to $1.2 \mathrm{~mm}, 1.8 \mathrm{~mm}$, and $2.4 \mathrm{~mm}(\mathrm{p}<0.0001)$.

Figure 1 shows a higher DC of dual-resin cement compared to the light-cured cement in all different thicknesses of ceramics, including without interposition $(p<0.0001)$. Figure 2 shows the DC of both resin cements according to the period of analysis and shows a statistically significant difference between the cements ( $p<0.0001)$, with the prevalence of higher DC in the dual-cured resin cement for all periods analyzed.

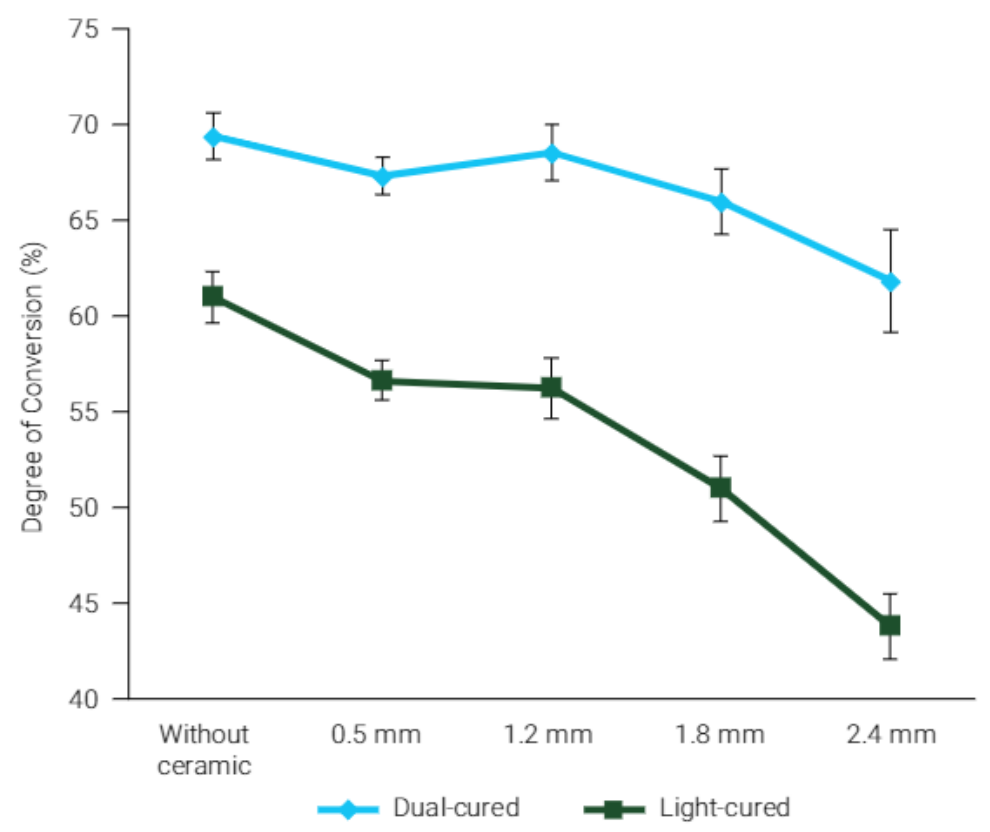

Figure 1. Degree of conversion of dual-cured and light-cured resin cements in relation to ceramic thickness.

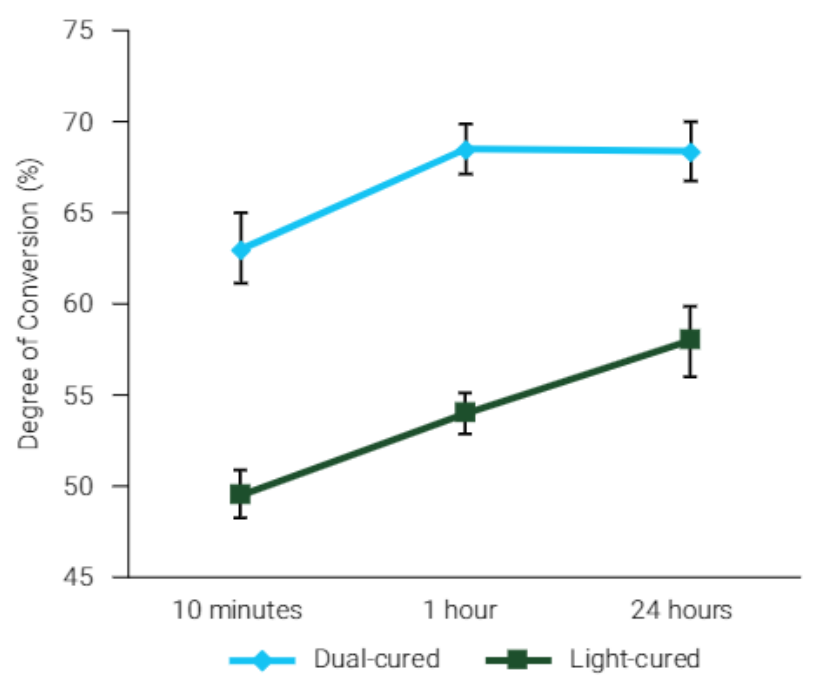

Figure 2. Degree of conversion of dual-cured and light-cured resin cements for the analysis period. 


\section{Discussion}

The conversion of the double bonds by photo-polymerization is dependent on a minimum of energy to excite the photoinitiator and produce a sufficient number of free radicals for polymerization. Although different levels of irradiation were transmitted through different thicknesses of ceramic, the findings suggest that this difference in energy is sufficient to produce significant differences in the degree of conversion as a function of thickness and time ${ }^{3}$. Thus, the three null hypothesis should be rejected, since the activation methods of the luting materials, evaluation times, and thicknesses of the ceramics influenced the DCs of resin cements.

Increased thickness of the ceramic feldspathic caused a decrease in the DCs of the resin cements (Tables 2 and 3 ), which could be compensated, in part, by use of a dual-cured cement in relation to the photoactivated cement. The lowest DC attributed to photoactivated resin cement for all ceramic groups, as well as in all periods analyzed, may be assigned to a low percentage of light that reached the cements (Figures 1 and 2) ) $^{14}$. The ceramic interposition between cement and the light source with a thickness of $1 \mathrm{~mm}$ decreased the light intensity at around $70 \%$, and the thicker the ceramic became, the more the light intensity gradually decreased until reaching almost total obstruction at $4 \mathrm{~mm}$ thickness ${ }^{28}$. Thus, particularly for the light-cured cement, the decrease of energy density of light, coinciding with the gradual increase of the ceramic thickness, could decrease the DC (Tables 2 and 3$)^{10}$.

The lower DC shown by resin cements after 10 minutes compared with other periods analyzed can be attributed to a delay in the initiation of the curing reaction ${ }^{11}$. In the case of dual-curing cements, the fast initial light exposure would cause changes in viscosity, hindering the migration of active radicals, responsible for induction of chemical polymerization, and thus slowing the conversion of monomers ${ }^{15}$. When initiated by light, the speed of the polymerization reaction of RelyX ARC is about 15 times faster in dual mode than with chemical curing ${ }^{17}$. The auto-polymerization mechanism is usually initiated by a reaction between benzoyl peroxide and a tertiary amine as a phenolic inhibitor is added to retard the polymerization. This delay in chemical reaction is expected, since it is necessary to provide adequate working time during restoration insertion, so that reaction inhibitors in material composition are provided satisfactory time to work $^{11}$.

However the lowest DCs of the cements measured in the early periods after cementation (Tables 2 and 3 ) may represent a clinical limitation. This period corresponds to the most critical challenge for the interface between the adhesive, tooth preparation, and indirect restoration, when stress created by occlusal adjustment and polishing procedures can affect the adhesion between them. In theory, the risk of detachment immediately after cementation is greater because the cementing agent has not yet reached its highest DC. The application of these forces and the disruption caused by the removal of excess luting agent, could affect adhesion, facilitating the development of cracks along the interface ${ }^{11,18}$. The differences in the delayed start of polymerization, especially for photoactivated cement (Table 3), could also be attributed to the content of inhibitors and catalysts used in these systems as well as the change in product viscosity ${ }^{12}$. Moreover, the dif- 
ficult migration of free radicals in the dual-cured cement caused by immediate photo-activation could have caused an increase in product viscosity, retarding the polymerization process ${ }^{15}$.

After 24 hours the DC was significantly higher than in the initial period. This indicates that chemical polymerization is effective in increasing the DC through time and can be explained by the light spectrum alteration of wavelengths transmitted through the interposition of ceramic discs ${ }^{3}$. However, some specimens can maintain their light spectral profiles and maintain the wavelength through the ceramic, while for other specimens, there can be higher absorption at specific wavelengths ${ }^{18}$.

The different answers of two polymerization methods may also have been caused by different camphorquinone photoinitiator concentrations. Although in the dual-cured cement there is no camphorquinone consumption before photo-polymerization is initiated, the component may have been substantially consumed by the initial radiation in the photo-activated cements ${ }^{29}$. Thus, its concentration may have become too low to allow post-polymerization to complete in time. However, not even reaching the polymerization DC level of dual-cured cement through time, also increased the photo-activation cement conversion through time (Figure 2). Moreover, because of their lower polymerization rate, dual-cured cements are more liable to the presence of a thicker layer uncured by contact with oxygen, compared to photo-cured cements ${ }^{19}$. The post-polymerization of this cement would promote the monomer conversion of this layer while increasing the final DC of the material ${ }^{19}$.

Thus, the development of restorative materials and techniques that enable higher conversion of the resin components is fundamental in the restorative process. An incomplete polymerization of luting agent could cause adverse clinical consequences, such as infiltration, postoperative sensitivity, discoloration, and secondary caries ${ }^{29}$. In this study, only the DC was studied as a parameter to describe the polymerization of the material. Further studies are necessary to test other physical, chemical and biological properties of dental cements and adhesive processes.

Based on the results of this study we can conclude that the thickness of ceramic directly influences the degree of conversion of light-cured and dual-cured resin cements with a tendency for the degree of conversion to decrease as the ceramic thickness increases. Both cements showed an increase in the degree of conversion over time, indicating a late polymerization, which could result in changes in clinical protocols currently used for cementation. Dual-cured resin cement showed higher conversion than light-cured cement in all analyzed situations.

\section{References}

1. Lee YK, Powers JM. Color changes of resin composites in the reflectance and transmitance modes. Dent Mater. 2007 Mar;23(3):259-64. doi: 10.1016/j.dental.2006.01.019.

2. Akgungor $\mathrm{G}$, AkkAyan B, Gaucher $\mathrm{H}$. Influence of ceramic thickness and polymerization mode of a resin luting agent on early bond strength and durability with a lithium disilicate-based ceramic system. J Prosthet Dent 2005 Sep;94(3):234-41. doi: 10.1016/j.prosdent.2005.04.020. 
3. Moraes RR, Correr-Sobrinho L, Sinhoreti MA, Puppin-Rontani RM, Ogliari FA, Piva E. Light-activation of resin cement through ceramic: relationship between irradiance intensity and bond strength to dentin. J Biomed Mater Res B Appl Biomater. 2008 Apr;85(1):160-5. doi: 10.1002/jbm.b.30928.

4. Novais VR, Raposo LH, Miranda RR, Lopes CC, Simamoto PC Junior, Soares CJ. Degree of conversion and bond strength of resin-cements to feldspathic ceramic using different curing modes. J Appl Oral Sci. 2017 Jan-Feb;25(1):61-8. doi: 10.1590/1678-77572016-0221.

5. Rashid H, Sheikh Z, Misbahuddin S, Kazmi MR, Qureshi S, Uddin MZ. Advancements in all-ceramics for dental restorations and their effect on the wear of opposing dentition. Eur J Dent 2016 Oct-Dec;10(4):583-8. doi: 10.4103/1305-7456.195170.

6. Awad D, Stawarczyk B, Ing D, Liebermann A, Ilie N. Translucency of esthetic dental restorative $\mathrm{CAD} / \mathrm{CAM}$ materials and composite resins with respect to thickness and surface roughness. J Prosthet Dent. 2015 Jun;113(6):534-40. doi: 10.1016/j.prosdent.2014.12.003.

7. Raigrodski AJ. Contemporary all-ceramic fixed partial dentures: a review. Dent Clin North Am. 2004 Apr;48(2):531-44.

8. Rosenblum MA, Schulman A. A review of all-ceramic restorations. J Am Dent Assoc. 1997 Mar;128(3):297-307.

9. Att W, Grigordiano M, Strub JR. Zro2 three-unit fixed partial dentures: comparison of failure load before and after exposure to a mastication simulator. J Oral Rehabil. 2007 Apr;34(4):282-90. doi: 10.1111/j.1365-2842.2006.01705.x.

10. Meng X, Yoshida K, Atsuta M. Influence of ceramic thickness mechanical properties and polimer estructure of dual-cured resin luting agents. Dent Mater. 2008 May;24(5):594-9. doi: 10.1016/j.dental.2007.06.014.

11. Arrais $C A G$, Giannini $M$, Rueggeberg FA. Kinetic analysis of monomer conversion in auto- and dual-polymerizing modes of commercial resin luting cements. J Prosthet Dent. 2009 Feb;101(2):128-36. doi: 10.1016/S0022-3913(09)60008-1.

12. Braga RR, Cesar PF, Gonzaga CC. Mechanical properties of resin cements with different activation modes. J. Oral Rehabil. 2002 Mar;29(3):257-62.

13. Ozyesil AG, Usumez, A, Gunduz B. The efficiency of different light sources to polymerize composite beneath a simulated ceramic restauration. J Prosthet Dent. 2004 Feb;91(2):151-7. doi: 10.1016/S0022391303007790.

14. Musanje L, Darvell BW. Curing-light attenuation in filled resin restorative materials. Dent Mater. 2006 Sep;22(9):804-17. doi: 10.1016/j.dental.2005.11.009.

15. Arrais CAG, Rueggeberg FA, Waller JL, de Goes MF, Giannini M. Effect of curing mode on the polymerization characteristics of dual-cured resin cement systems. J Dent. 2008 Jun; 36(6):418-26. doi: 10.1016/j.jdent.2008.02.014.

16. Silikas N, Eliades G, Watts DC. Light intensity effects on resin-composite degree of conversion and shrinkage strain. Dent Mater. 2000 Jul;16(4):292-6.

17. Lee IB, An W, Chang J, Um CM. Influence of ceramic thickness and curing mode on the polymerization shrinkage kinetics of dual-cured resin cements. Dent Mater. 2008 Aug;24(8):1141-7. doi: 10.1016/j.dental.2008.03.015.

18. Koch A, Kroeger M, Hartung M, Manetsberger I, Hiller KA, Schmalz G, et al. Influence of ceramic translucency on curing efficacy of different light-curing units. J Adhes Dent. 2007 Oct;9(5):449-62.

19. Ruyter IE. Unpolymerized surface layers on sealants. Acta Odontol Scand. 1981;39(1):7-32.

20. Att W, Kurun S, Gerds T, Strub JR. Fracture resistance of single-tooth implant-supported all-ceramic restorations: an in vivo study. J Prosthet Dent. 2006 Feb;95(2):111-6. doi: 10.1016/j.prosdent.2005.12.003. 
21. Addison O, Fleming GJ. The influence of cement lute, thermocycling and surface preparation on the strength of a porcelain laminate veneering material. Dent Mater. 2004 Mar;20(3):286-92. doi: 10.1016/S0109-5641(03)00105-2.

22. Cattel MJ, Knowless JC, Clarke RL, Lynch E. The biaxial flexural strength of two pressable ceramic systems. J Dent. 1999 Mar;27(3):183-96.

23. Albakry M, Guazzato M, Swain MV. Biaxial flexural strength, elastic moduli, and x-ray diffraction characterization of three pressable all-ceramic materials. J Prosthet Dent. 2003 Apr;89(4):374-80. doi: $10.1067 / \mathrm{mpr} .2003 .42$.

24. Heffernan MJ, Aquilino SA, Diaz-Arnold, Haselton DR, Stanford CM, Vargas MA. Relative translucency of six all-ceramic systems. Part I: core materials. J Prosthet Dent. 2002 Jul;88(1):4-9.

25. Heffernan MJ, Aquilino SA, Diaz-Arnold, Haselton DR, Stanford CM, Vargas MA. Relative translucency of six all-ceramic systems. Part II: core and veneer materials. J Prosthet Dent. 2002 Jul;88(1):10-5.

26. Ausiello P, Apicella A, Davidson CL. Effect of adhesive layer properties on stress distribution in composite restorations - a 3D finite element analysis. Dent Mater. 2002 Jun; 18(4):295-303.

27. Oh W, Anusavice KJ. Effect of connector design on the fracture resistance of all-ceramic fixed partial dentures. J Prosthet Dent. 2002 May;87(5):536-42.

28. Lee IB, Cho BH, Son HH, Um CM, Lim BS. The effect of consistency, specimen geometry and adhesion on the axial polymerization shrinkage measurement of light cured composites. Dent Mater. 2006 Nov;22(11):1071-9. doi: 10.1016/j.dental.2005.08.012.

29. Andrzejewska E, Linden LA, Rabek JF. The role of oxygen in camphorquinone-initiated photopolymerization. Macromol Chem Phys. 1998;199(3):441-9. 